\title{
The use of average Pavlov ratio to predict the risk of post operative upper limb palsy after posterior cervical decompression Koon-Man Sieh*1, Siu-Man Leung ${ }^{1}$, Judy Suk Yee Lam² ${ }^{2}$ Kai Yin Cheung ${ }^{1}$ and Kwai Yau Fung ${ }^{1}$
}

Address: ${ }^{1}$ Department of Orthopaedics and Traumatology, Alice Ho Mui Ling Nethersole Hospital, Tai Po, NT, Hong Kong SAR, PR China and 2Department of Diagnostic Radiology and organ Imaging, The Chinese University of Hong Kong, Prince of Wales Hospital, Shatin, NT, Hong Kong SAR, PR China

Email: Koon-Man Sieh* - siehkm1@yahoo.com.hk; Siu-Man Leung -dr.sm.leung@hotmail.com; Judy Suk Yee Lam - judysylam@yahoo.com; Kai Yin Cheung - kenkyc@cuhk.edu.hk; Kwai Yau Fung - kyfung@ort.cuhk.edu.hk

* Corresponding author

Published: 7 July 2009

Journal of Orthopaedic Surgery and Research 2009, 4:24 doi:10.1 I86/I749-799X-4-24

This article is available from: http://www.josr-online.com/content/4/I/24

(C) 2009 Sieh et al; licensee BioMed Central Ltd.

This is an Open Access article distributed under the terms of the Creative Commons Attribution License (http://creativecommons.org/licenses/by/2.0), which permits unrestricted use, distribution, and reproduction in any medium, provided the original work is properly cited.

\section{Abstract}

Study Design: A retrospective study was conducted to study the post operative upper limb palsy after laminoplasty for cervical myelopathy.

Objective: To identify a reliable and simple preoperative radiological parameter in predicting the risk of post operative upper limb palsy.

Background: Post operative upper limb palsy is one of the causes of patient dissatisfaction after surgery. There had been no simple, standard preoperative radiological parameters reliably predict the occurrence of this problem.

Materials and methods: Seventy-four patients received posterior cervical decompression from 1998 to 2008. Medical record and preoperative radiological information were evaluated. Clinical presentations of the palsy were described. The relationship between the occurrence of palsy and different preoperative radiological information is analyzed.

Results: Eighteen patients (24.3\%) presented with post operative upper limb palsy. Majority of patients presented with dysesthesia (17//8) and with deficit of the C5 segment (17//8). Ten patients presented with pure dysesthesia and 8 patients presented with mixed motor-sensory deficit and dysesthesia. Multilevel involvement was exclusively presented in patients with motor weakness. A longer duration of symptom ( $16.7 \mathrm{Vs} 57.2$ days) was noticed in patients in the motor deficit group. Average Pavlov ratio less then $0.65(P=0.027$, Odds Ratio $=3.68)$ and compression at the $C 3 / 4$ in preoperative MRI image $(P=0.025$, Odds Ratio $=6)$ were significant risk factors for development of this problem.

Conclusion: Post operative upper limb palsy is not uncommon and thorough preoperative explanation is important. There is a spectrum of clinical presentation and patients with multi-level involvement and motor deficit are associated with poorer prognosis. Average Pavlov ratio $<0.65$ and compression at $\mathrm{C} 3 / 4$ segment on preoperative MRI image are simple and reliable preoperative predictor for the development of this problem. 


\section{Introduction}

Cervical myeloradiculopathy caused by compression of the cervical cord by various pathologies remains one of the major disease entities of the cervical spine. Laminoplasty is simple, safe and effective in the treatment of cervical myeloradiculopathy. This technique gained widespread acceptance and popularity since the development of 'expansive open-door laminoplasty' by Hirabayashi in 1977 [1]. This has formed the basis for the development of various technique modifications.

Development of neurological deterioration after cervical operation is a major clinical problem. Post operative upper limb palsy, predominantly of the C5 segment, after cervical laminoplasty has become one of the most notorious complications affecting patients' post operative satisfaction because of the disabling symptom of paralysis and pain [2-14]. There is strong evidence on the association between post operative upper limb palsy and laminoplasty. The reported incidence of post operative upper limb palsy ranged from $0-30 \%$ [15]. There has been great disparity in the incidence and definition of this complication. Although the deficit is usually transient $[1-4,9,11]$, long recovery time and persistent neurological symptoms had been reported $[5-8,10,13]$. Moreover, there has not been simple, standard preoperative radiological parameter reliably predicting the occurrence of this complication so far. The objective of the current study is to describe the clinical feature and identify a preoperative predictor for the development of post operative upper limb palsy.

\section{Materials and methods}

A retrospective study of 74 patients undergoing posterior decompression for cervical myeloradiculopathy from 1998 to 2008 in Alice Ho Mui Ling Nethersole Hospital was conducted. There were 48 men and 26 women with mean age of 60.9 (23 to 89). The cause of cervical myeloradiculopathy included cervical spondylotic myelopathy $(n=52)$, ossification of posterior longitudinal ligament $(\mathrm{n}=16)$, and cervical disc protrusion in developmental cervical stenosis $(n=6)$. Expansive open-door laminoplasty was performed and 6 patients received additional posterior instrumented fusion for concomitant instability. Medical records were reviewed by the first author (SKM). Table 1 shows their demographic characteristics and the type and level of decompression.

Postoperative upper limb palsy was defined as having deterioration of motor function by at least one level in standard manual muscle testing (MMT) and/or new sensory disturbance and dysesthesia with dermatomal distribution after the operation. The level of neurologic involvement was determined by the sensory dermatomal distribution and myotome involvement as follows: deltoid and biceps brachii - C5 segment, wrist extensors - C6 segment, triceps - C7 segment, wrist flexors and grip power - C8 segment, intrinsic muscles - T1 segment.

Severity of clinical symptom was described using an evaluation scores established by the Japanese Orthopaedic Association (JOA Score, Table 2). The total preoperative and postoperative JOA scores and the recovery rate, by Hirabayashi method were also calculated.

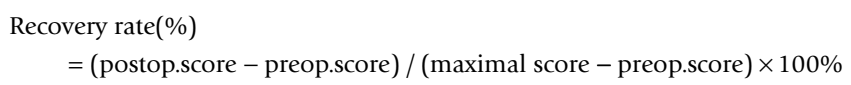

Radiologic parameters, including developmental sagittal canal diameter and vertebral body diameter from C3 to C6 were measured using a digital calliper on standard lateral cervical radiographs. The Pavlov ratio at each level and the average Pavlov ratio, calculated by averaging the Pavlov ratio at C3 to C6 level, were calculated for each patient [16-18]. (Figure 1) The alignment of the cervical spine was classified into lordosis, straight alignment, sigmoid alignment and kyphosis in accordance with the criteria of Toyama [19]. MRI was performed in every patient before the operation. Compression of cervical cord was defined as any deformation of the cervical cord shown in axial and sagittal scan of the MRI (Figure 2). The level of compression and the multiplicity of compression were also evaluated. The presence and location of high-signal intensity area (HIA) in the spinal cord on T2-weighed MRI image were recorded (Figure 3 ). These radiologic parameters were investigated by SKM before evaluation of the clinical notes (to minimized observer bias), and independently by an orthopaedic specialist (LSM), and a diagnostic radiologist (LJS). The mean of the three measurements was taken as final measurement to minimal inter-observer error.

\section{Statistical analysis}

The differences in demographic characteristics and radiologic parameters, extension of decompression and degree of recovery between those with and without postoperative upper limb palsy were tested by t-test and $\chi^{2}$ test as appropriate. Univariated analyses were performed to estimate the odds ratios of various radiologic parameters, extension of decompression and various risk factors for development of postoperative upper limb palsy. Statistical significance was defined by a $p$-value of less than 0.05 . All statistical analyses were performed using by SPSS version 16.

\section{Results}

\section{Post operative upper limb palsy}

Eighteen patients $(24.3 \%)$ developed post operative upper limb palsy between 1 and 7 days after surgery (mean 2.6 days). There was no report on the deterioration of neurological status immediately after the operation. 
Table I: Demographic and other characteristics of the patients

\begin{tabular}{|c|c|c|}
\hline & Patient without palsy $(n=56)$ & Patient with Palsy $(n=18)$ \\
\hline $\operatorname{Sex}(M / F)$ & $36 / 20$ & $12 / 6$ \\
\hline Mean age at surgery (years) & 60.63 & 61.61 \\
\hline Duration of symptom before operation (months) & 12.42 & 15.06 \\
\hline \multicolumn{3}{|l|}{ Disease etiology (\%) } \\
\hline - CSM & $40(71.4)$ & $12(66.7)$ \\
\hline - OPLL & $11(19.6)$ & $5(27.8)$ \\
\hline - PID & $5(8.9)$ & I (5.6) \\
\hline \multicolumn{3}{|l|}{ Type of operation (\%) } \\
\hline - Laminoplasty & $53(94.6)$ & $15(83.3)$ \\
\hline - Posterior decompression with internal fixation & $3(5.4)$ & $3(16.7)$ \\
\hline \multicolumn{3}{|l|}{ Extent of decompression (\%) } \\
\hline$-\mathrm{C} 2-\mathrm{C} 7$ & $\mathrm{I}(\mathrm{I} .8)$ & $0(0)$ \\
\hline$-\mathrm{C} 3-\mathrm{C7}$ & $25(44.6)$ & $9(50)$ \\
\hline$-\mathrm{C} 3-\mathrm{C} 6$ & $21(37.5)$ & $8(44.4)$ \\
\hline$-\mathrm{C} 3-\mathrm{C5}$ & $4(7.1)$ & $0(0)$ \\
\hline$-\mathrm{C} 4-\mathrm{C7}$ & $3(5.4)$ & $0(0)$ \\
\hline$-\mathrm{C} 4-\mathrm{C} 6$ & $2(3.6)$ & I (5.6) \\
\hline Mean Preoperative JOA score & 10.55 & 11.22 \\
\hline Mean Postoperative JOA score & 13.66 & 14.22 \\
\hline Recovery rate (\%) & $\underline{52.37}$ & $\underline{48.34}$ \\
\hline
\end{tabular}

CSM = cervical spondylotic myelopathy; OPLL = ossification of the posterior longitudinal ligament; PID = Protrusion of cervical disc in developmental cervical stenosis

*All statistically not significant

There were no significant difference in gender, age at surgery, etiology, duration of symptom before surgery, level of decompression, pre- and postoperative JOA scores and recovery rate between patients with and without postoperative upper limb palsy (Table 1 ).

Ten patients presented with pure dysesthesia over the C5 dermatome and eight patients presented with motor weakness mixed with sensory deficit and dysesthesia. (Figure 4) All except one patient had C5 level involvement. The level of cervical segment involvement was showed in table 3. Multi-level involvement occurred exclusively in patients with motor weakness. Majority of these patients (7/8) presented with mixed dysesthesia, motor and sensory deficit. Twelve patients presented with unilateral symptom. Six patients presented with bilateral symptoms.

All except one patient recovered completely from their symptom, with an average of 33.1 days (1-182 days). Twelve of the 18 patients required simple analgesic and six patients required anxiolytic and gabapentin for symptomatic relief. One patient presented with bilateral shoul- der pain on the first post operative day followed by progressive weakness of both upper limb. Improvement was slow and functional recovery $(\mathrm{MMT}>3 / 5)$ was not achieved in the latest follow-up on the $4^{\text {th }}$ post operative month. Those having motor weakness was older (66 Vs 58 years) and suffering from longer duration of symptom (5182 days, mean $=57.3$ days) than patient with pure dysesthesia (1-95 days, mean $=16.7$ days). The difference was short of statistical significance $(p=0.082)$. (Table 4$)$

\section{Radiological data}

The mean Pavlov ratio at each level and the Average Pavlov ratio were smaller in patient with post operative upper limb palsy but statistical significance was not able to demonstrate (Table 5). Figure 5 shows the distribution of Average Pavlov ratio and the quartile value of our patients. Table 6 shows the results of the univariate analyses. Patients having severe cervical canal stenosis, defined as an Average Pavlov ratio of less than $1^{\text {st }}$ quartile, (0.65) (OR $3.38, p=0.027$ ) were significantly more likely to develop postoperative upper limb palsy. 
Table 2: Japanese Orthopaedic Association Score

\begin{tabular}{|c|c|}
\hline JOA SCORE & \\
\hline \multirow[t]{5}{*}{ 1. Motor function of the upper extremity } & 0. Impossible to eat with chopsticks or spoon \\
\hline & I. Possible to ear with spoon, but not with chopsticks \\
\hline & 2. Possible to eat with chopsticks, but inadequate \\
\hline & 3. Possible to eat with chopsticks, but awkward \\
\hline & 4. Normal \\
\hline \multirow[t]{5}{*}{ II. Motor function of the lower extremity } & 0. Impossible to walk \\
\hline & I. Needs cane or aid on flat ground \\
\hline & 2. Needs cane or aid only on stairs \\
\hline & 3. Possible to walk without cane or aid but slowly \\
\hline & 4. Normal \\
\hline \multirow[t]{6}{*}{ III. Sensory function } & A. Upper extremity \\
\hline & 0 . Apparent sensory loss \\
\hline & I. Minimal sensory loss \\
\hline & 2. Normal \\
\hline & B. Lower extremity (same as A) \\
\hline & Trunk (same as A) \\
\hline \multirow[t]{4}{*}{ IV. Bladder function } & 0. Complete retention \\
\hline & I. Severe disturbance (sense of retention, dribbling, incomplete continence) \\
\hline & 2. Mild disturbance (urinary frequency, urinary hesitancy) \\
\hline & 3. Normal \\
\hline
\end{tabular}

Compression of cervical cord in preoperative MRI was most commonly occurring at the mid-cervical level (Table 6). C4/5 level in 56 patients $(71.8 \%)$, followed by $\mathrm{C} 5 / 6$ in 52 patients $(66.7 \%)$ and $\mathrm{C} 3 / 4$ in 48 patients $(64.9 \%)$. However, compression at $\mathrm{C} 3 / 4$ level is showed to associate with higher risk of occurrence of palsy (OR 6, p = 0.025 ). Multiplicity of compression, defined by 3 or more compression from preoperative MRI, showed higher rate of development of post operative upper limb palsy (73.2\% Vs $48.2 \%$ ) with marginal statistical significance (p $=0.082$ ) . The association between palsy and preoperative alignment, intramedullary high-signal intensity area (HIA) on preoperative T2-weighted MRI were not significant.

\section{Discussion}

Post operative upper limb palsy after cervical laminoplasty posterior has raised substantial concern in the past 20 years but controversies still remain in the nomenclature, pathophysiology and defining the risk factors for the development of this significant complication. 'Post operative C5 palsy', defined by unilateral paralysis of the deltoid and biceps muscles without sensory disturbance $[2,3,20]$ is one of the commonly used definitions among surgeons. At the same time, there are considerable concerns about the multilevel motor paralysis after the surgery $[4-10,21,22]$, which led to the evolution of different nomenclatures like 'Segmental motor paralysis' [4-6], 'Post operative muscle weakness of the upper extremities' [8], 'Post operative motor paralysis of the upper limb' [10] and 'upper extremity palsy' [7,22]. Moreover, some authors who also include pain and sensory disturbance in describing this problem $[5,7,9,11,13,14]$. In this study, we defined postoperative upper limb palsy as having deterioration of motor function by at least one level in standard manual muscle testing (MMT) and/or new sensory disturbance and dysesthesia with dermatomal distribution after the operation.

Narrow spinal canal is associated with higher risk for the development of cervical myelopathy [16-18]. Edwards et al. defined narrow spinal canal by direct measurement of the midcervical diameter from standard lateral cervical radiograph. Measurement less then $13 \mathrm{~mm}$ is prone to development cervical myelopathy [18]. The use of Pavlov ratio eliminated the discrepancy of magnification and had been generally accepted an essential radiological parameter in management of cervical myeloradiculopathy. Pavlov ratio less then 0.82 are considered stenotic [17] and are associated with a higher risk of cervical myelopathy. Yue et al. echoed the work of Pavlov and concluded that Average Pavlov ratio might be a useful predictor to cervical myelopathy [17]. However, the association of narrow spinal canal with the risk of post operative upper limb palsy has not been clearly established.

Recognizing the substantial proportion of multi-level involvement in our patient with the post operative upper limb palsy, we hypothesize that pathological insults to the cervical cord adopted a similar 'multi-level' fashion. We 


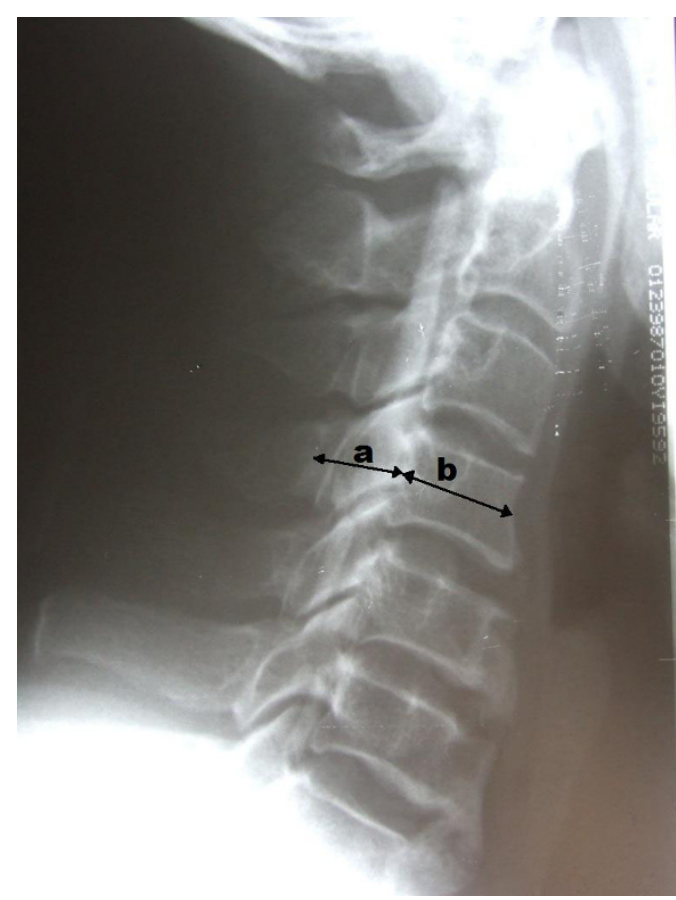

Figure I

The sagittal diameter of the spinal canal (a) is measured from the posterior point of the corresponding spinal laminar line. The sagittal diameter of the vertebral body (b) is measured at the midpoint, from the anterior surface to the posterior surface. The spinal canal/vertebral body ratio is determined with the formula $a / b$ as Pavlov ratio.

also hypothesize that patients with developmental cervical stenosis, implied by a small Average Pavlov ratio, will have higher risk for developing postoperative palsy. A developmentally narrowed spinal canal made cord compression more likely. On the other hand, there may be inherent factors associating with the narrowing which render the cord more susceptible to pathological insults, e.g. peculiar blood supply, or as a result of reperfusion after decompression of multi-level compression [15].

Since our patients were all suffering from symptomatic cervical myeloradiculopathy, the distribution of Average Pavlov ratio is expected to be skewed instead of normal, which justified the transformation of the Average Pavlov ratio into a categorical variable. We used the $1^{\text {st }}$ quartile as the cut off for defining extremely narrow spinal canal, for subsequent analyses (Figure 5). We are able to show a significantly higher risk of developing postoperative palsy in patients having an Average Pavlov ratio of less then 0.65 with an odds ratio of 3.68. Moreover, there was a higher rate of post operative upper limb palsy in patient with 3 or more compression on preoperative MRI with marginal statistical significance. These results support our assump-

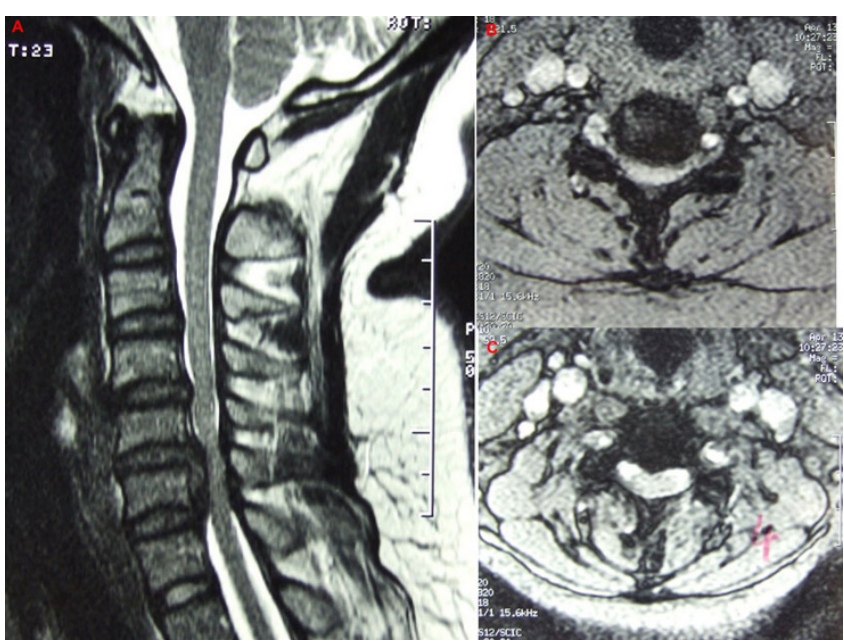

Figure 2

Preoperative MRI image showing compression of the cervical cord at C5/6. A, sagittal T2-weighted MRI image. $B$, corresponding axial T2-weighted MRI image showing deformation of the $\mathrm{C} 5 / 6$ by the compression. $\mathrm{C}$, no deformation of the cord at $C 4 / 5$.

tion that an extremely narrow cervical spinal canal is prone to development of post operative upper limb palsy.

Majority of our patients present with dysesthesia (17/18) and had neurologic deficit involving the C5 segment (17/ 18). We showed compression at the C3/4 level is strongly associated with the development of palsy. Since anatomi-

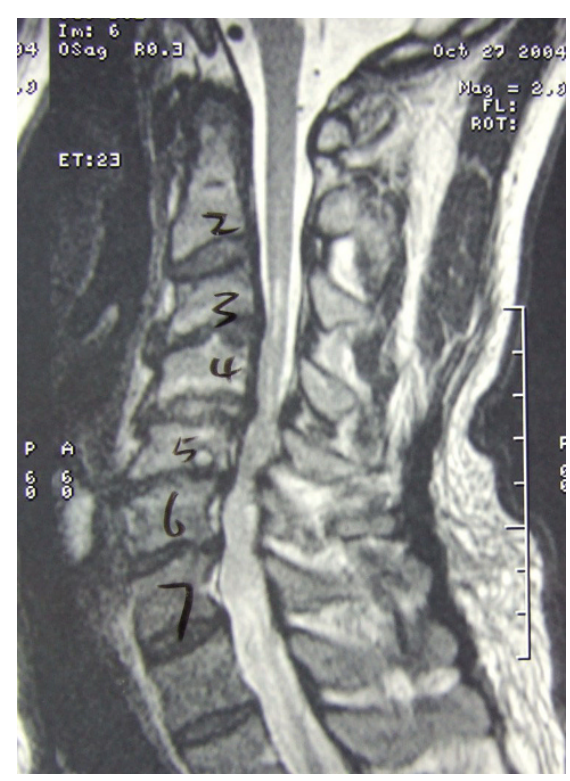

Figure 3

High-signal intensity area in the C3/4 segment in T2weighted MRI image. 
Table 3: Summary of patients with post operative upper limb palsy

\begin{tabular}{|c|c|c|c|c|c|c|c|c|c|c|}
\hline \multirow[t]{2}{*}{ Case no. } & \multirow[t]{2}{*}{ Age $(y r) / S e x$} & \multirow[t]{2}{*}{ Etiology } & \multicolumn{3}{|c|}{ Presentation } & \multirow[t]{2}{*}{ Onset (days) } & \multirow{2}{*}{$\begin{array}{l}\text { Duration of } \\
\text { recovery } \\
\text { (days) }\end{array}$} & \multirow[t]{2}{*}{ Laterality } & \multirow{2}{*}{$\begin{array}{c}\text { Level of } \\
\text { involvement }\end{array}$} & \multirow{2}{*}{$\begin{array}{c}\text { HIA on } \\
\text { preop. MRI }\end{array}$} \\
\hline & & & Dysesthesia & $\begin{array}{c}\text { Sensory } \\
\text { deficit }\end{array}$ & $\begin{array}{l}\text { Motor deficit } \\
\text { (MMT) }\end{array}$ & & & & & \\
\hline 1 & $72 / M$ & CSM & Yes & No & No & 5 & 2 & Left & $\mathrm{C} 5$ & - \\
\hline 2 & $80 / M$ & CSM & Yes & No & $\begin{array}{c}\text { Yes } \\
(4 \text { to }-3)\end{array}$ & 7 & 42 & Left & $\mathrm{C} 5$ & $\mathrm{C} 3 / 4, \mathrm{C} 6 / 7$ \\
\hline 3 & $7 I / F$ & CSM & Yes & No & Yes (5 to 4$)$ & 2 & 42 & Bilateral & $\mathrm{C} 5, \mathrm{C} 8$ & $\mathrm{C} 5$ \\
\hline 4 & $54 / F$ & CSM & Yes & No & No & 1 & 8 & Left & $\mathrm{C5}$ & $\mathrm{C} 6 / 7$ \\
\hline 5 & $50 / M$ & OPLL & Yes & Yes & Yes (5 to 3 ) & 1 & 31 & Right & $\mathrm{C} 6, \mathrm{C7}$ & $\mathrm{C} 3 / 4$ \\
\hline 6 & $74 / M$ & CSM & Yes & No & No & 3 & 95 & Right & $\mathrm{C} 5$ & $\mathrm{C} 3 / 4, \mathrm{C} 5 / 6$ \\
\hline 7 & $5 I / M$ & CSM & Yes & No & Yes (5 to 4$)$ & 4 & 5 & Right & C5-7 & $C 4 / 5$ \\
\hline 8 & $50 / M$ & PID & Yes & No & No & 3 & 1 & Right & C5 & C3-5 \\
\hline 9 & $54 / M$ & CSM & Yes & No & No & 6 & I & Right & $\mathrm{C5}$ & - \\
\hline 10 & $78 / M$ & CSM & Yes & No & $\begin{array}{c}\text { Yes } \\
(4 \text { to }-3)\end{array}$ & I & 21 & Bilateral & C5-6 & $C 5 / 6$ \\
\hline 11 & $49 / F$ & OPLL & Yes & No & No & 2 & 2 & Left & $\mathrm{C5}$ & - \\
\hline 12 & $68 / F$ & OPLL & Yes & Yes & Yes (5-4) & 1 & 182 & Bilateral & $\mathrm{C5}, \mathrm{C} 8, \mathrm{TI}$ & - \\
\hline 13 & $6 \mathrm{I} / \mathrm{F}$ & OPLL & Yes & No & No & 1 & 15 & Left & C5 & $C 4 / 5$ \\
\hline 14 & $49 / M$ & CSM & Yes & No & No & I & 27 & Bilateral & $\mathrm{C} 5$ & - \\
\hline 15 & $59 / F$ & OPLL & Yes & No & No & I & 11 & Bilateral & $\mathrm{C} 5$ & - \\
\hline 16 & $84 / M$ & CSM & No & No & Yes (4-3) & 4 & 15 & Left & C5-7 & $\mathrm{C} 3 / 4, \mathrm{C} 6 / 7$ \\
\hline 17 & $60 / M$ & CSM & Yes & No & No & 2 & 5 & Right & $\mathrm{C5}$ & $\mathrm{C} 4 / 5, \mathrm{C} 5-6$ \\
\hline 18 & $45 / M$ & CSM & Yes & No & Yes $(5-0)$ & I & 120 & Bilateral & C5-TI & $\mathrm{C} 3 / 4, \mathrm{C} 6 / 7$ \\
\hline
\end{tabular}

CSM = cervical spondylotic myelopathy; OPLL = ossification of the posterior longitudinal ligament; PID = Protrusion of cervical disc in developmental cervical stenosis; MMT = Manual muscle testing; HIA = T2 high-signal intensity area in the spinal cord;

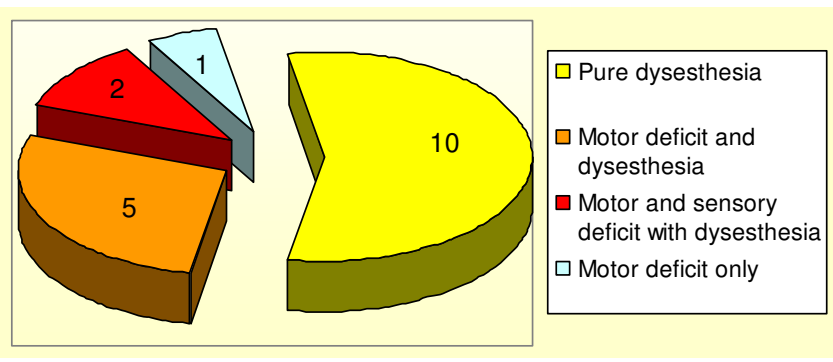

Figure 4

Distribution of presentation in patients with post operative upper limb palsy. cal study showed C3/4 level corresponds to the C5 cord segment [23], it is reasonable to assume compression of C5 segment is a strong contributing factor in the development of post operative upper limb palsy and this also explained the predilection of $\mathrm{C} 5$ neurologic dysfunction.

There is no significant difference in JOA score and recovery rate between patients with and without the palsy in this study. Since the effect of post operative upper limb palsy is transient, most of the patients had already recovered during the follow up review in this retrospective study. Further this may be the limitation of the JOA score 
Table 4: Characteristic between patients with and without motor weakness

\begin{tabular}{lccc}
\hline & $\begin{array}{c}\text { Pure dysesthesia } \\
(\mathrm{n}=10)\end{array}$ & $\begin{array}{c}\text { Dysesthesia with motor deficit } \\
(\mathrm{n}=8)\end{array}$ & 65.9 \\
\hline Mean age (years) & 58.2 & 57.3 & 0.199 \\
\hline Mean recovery time (days) & 16.7 & $6: 2$ & 0.082 \\
\hline Sex (M/F) & $6: 4$ & $7(87.5)$ & 0.502 \\
\hline HIA in T2-weighted MRI (\%) & $5(50)$ & 0.152 \\
\hline
\end{tabular}

Table 5: Pavlov ratios of patients with and without postoperative upper limb palsy

\begin{tabular}{lcc}
\hline & $\begin{array}{c}\text { Patient without palsy } \\
(\mathrm{n}=56)\end{array}$ & $\begin{array}{c}\text { Patient with palsy } \\
(\mathrm{n}=18)\end{array}$ \\
\hline Pavlov ratio (mean) & & $P$ \\
C3 & 0.7125 & 0.6916 \\
C4 & 0.6870 & 0.6701 \\
C5 & 0.6836 & 0.6805 \\
C6 & 0.7198 & 0.6783 \\
Average & 0.7017 & 0.6804 \\
\hline
\end{tabular}

Table 6: Odds ratio of potential risk factors for development of postoperative upper limb palsy

\begin{tabular}{|c|c|c|c|c|}
\hline & $\begin{array}{l}\text { Patient without palsy } \\
\qquad(\mathrm{n}=56)\end{array}$ & $\begin{array}{l}\text { Patient with palsy } \\
\qquad(\mathrm{n}=18)\end{array}$ & OR & $p$ \\
\hline Average Pavlov ratio $<0.65$ & $10(17.9)$ & $8(44.4)$ & 3.68 & 0.027 \\
\hline \multicolumn{5}{|l|}{ Level of compression in Preoperative MRI (\%) } \\
\hline $\mathrm{C} 2 / 3(\%)$ & $3(5.4)$ & $\mathrm{I}(5.6)$ & 1.039 & 0.974 \\
\hline C3/4 (\%) & $32(57.1)$ & $16(88.9)$ & 6 & 0.025 \\
\hline C4/5 (\%) & $40(7 \mid .4)$ & $16(88.9)$ & 3.2 & 0.149 \\
\hline C5/6 (\%) & $42(75.0)$ & $10(55.6)$ & 0.417 & 0.122 \\
\hline C6/7 (\%) & $25(44.6)$ & $10(55.6)$ & 1.55 & 0.421 \\
\hline $\mathrm{C} 7 / \mathrm{TI}(\%)$ & $\mathrm{I}(\mathrm{l} .8)$ & $0(0)$ & & \\
\hline 3 or more compression levels in MRI (\%) & $27(48.2)$ & $13(72.2)$ & 2.79 & 0.082 \\
\hline HIA in T2 weighted MRI image (\%) & $44(78.6)$ & $11(6 I . I)$ & 0.955 & 0.943 \\
\hline
\end{tabular}




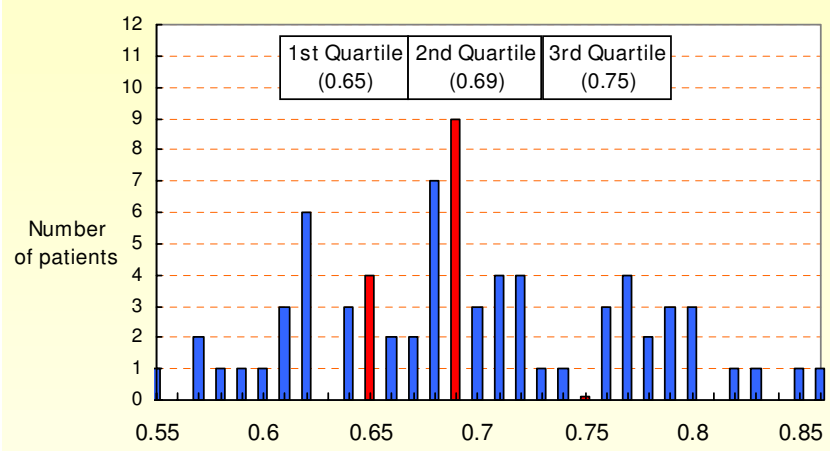

Figure 5

Distribution of Average Pavlov ratio for all patients and the Quartile values.

in reflecting the functional disturbance attributed by the post operative upper limb palsy.

Although many researchers has suggested different preoperative and intraoperative monitor in detecting the occurrence and evaluating the risk of post operative upper limb palsy, they usually involved specially trained personnel and sophisticated equipment [2,11,20-22]. In our pilot study using measuring ruler in measuring the Average Pavlov ratio, same conclusion (0.65) can be reached. This suggested simple measuring technique is also applicable when using Average Pavlov ratio to predict the risk of occurrence of palsy. Our study is able to demonstrate these two preoperative radiological parameters are simple, reliable in predicting this significant post operative complication of posterior cervical decompression.

Finally, this is the drawback of the current study of small population size. The dose-effect of spinal canal narrowing to the development of post operative upper limb palsy was not able to demonstrate and causing statistical insignificant or marginal significant in variable parameters.

\section{Conclusion}

Post operative upper limb palsy is a significant post operative complication of cervical posterior decompression that thorough preoperative explanation is important. Spectrum of presentation from pure dysesthesia to multilevel, motor sensory dysfunction is demonstrated. Patient presented with multi-level involvement and motor dysfunction is associated with longer recovery period. Average Pavlov Ratio of less then 0.65 and cervical cord compression of $\mathrm{C} 3 / 4$ level in preoperative MRI could be simple and reliable predictors for the development of post operative upper limb palsy

\section{Competing interests}

The authors declare that they have no competing interests.

\section{Authors' contributions}

All authors had substantial contributions to conception and design of the study and giving final approval to the manuscript. KMS, SML and JSYL participated in the data acquisition. KMS is responsible for data interpretation and writing of the manuscript. All authors have read and approved the final manuscript.

\section{Acknowledgements}

The authors cordially appreciate the assistance from the nursing staff of the Department of Orthopaedics and Traumatology, Alice Ho Mui Ling Nethersole Hospital in preparation of clinical materials. We would like to appreciate $\mathrm{Dr}$. PS Ng for his assistance in statistical analysis of the data in this study.

\section{References}

I. Hirabayashi K, Watanabe K, Wakano K, Suzuki N, Ishii Y: Expansive Open-Door Laminoplasty for Cervical Spinal Stenotic Myelopathy. Spine 1983, 8(7):693-9.

2. Tanaka N, Nakanishi K, Fujiwara Y, Kamei N, Ochi M: Postoperative segmental C5 palsy after cervical laminoplasty may occur without intraoperative nerve injury: a prospective study with transcranial electric motor-evoked potentials. Spine 2006, 3 I (26):30I3-7.

3. Minoda $Y$, Nakamura $H$, Konishi S, Nagayama R, Suzuki E, Yamano $Y$, Takaoka K: Palsy of the C5 nerve root after midsagittal-splitting laminoplasty of the cervical spine. Spine 2003, 28(II): II 23-7.

4. Chiba K, Ogawa Y, Ishii K, Takaishi H, Nakamura M, Maruiwa H, Matsumoto $M$, Toyama $Y$ : Long-term results of expansive opendoor laminoplasty for cervical myelopathy - average I4-year follow-up study. Spine 2006, 3 I (26):2998-3005.

5. Sakaura H, Hosono N, Mukai Y, Fujii R, Iwasaki M, Yoshikawa H: Segmental motor paralysis after cervical laminoplasty: a prospective study. Spine 2006, 3 I (23):2684-8.

6. Chiba K, Toyama Y, Matsumoto M, Maruiwa H, Watanabe M, Hirabayashi K: Segmental motor paralysis after expansive opendoor laminoplasty. Spine 2002, 27(19):2 108-15.

7. Hasegawa K, Homma T, Chiba Y: Upper extremity palsy following cervical decompression surgery results from a transient spinal cord lesion. Spine 2007, 32(6):E1 97-202.

8. Satomi K, Ogawa J, Ishii Y, Hirabayashi K: Short-term complications and long-term results of expansive open-door laminoplasty for cervical stenotic myelopathy. Spine J 200I, I(I):26-30.

9. Komagata M, Nishiyama M, Endo K, Ikegami H, Tanaka S, Imakiire A: Prophylaxis of $C 5$ palsy after cervical expansive laminoplasty by bilateral partial foraminotomy. Spine J 2004, 4(6):650-5.

10. Seichi A, Takeshita K, Kawaguchi H, Nakajima S, Akune T, Nakamura $\mathrm{K}$ : Postoperative expansion of intramedullary high-intensity areas on T2-weighted magnetic resonance imaging after cervical laminoplasty. Spine 2004, 29( I3): 1478-82.

II. Sasai K, Saito T, Akagi S, Kato I, Ohnari H, lida H: Preventing C5 palsy after laminoplasty. Spine 2003, 28(17): 1972-7.

12. Kaminsky SB, Clark CR, Traynelis VC: Operative treatment of Cervical Spondylotic Myelopathy and Radiculopathy: A comparison of Laminectomy and Laminoplasty at five year average follow-up. lowa Orthop J 2004, 24:95-105.

13. Uematsu Y, Tokuhashi Y, Mtsuzaki H: Radiculopathy after Laminoplasty of the Cervical Spine. Spine 1998, 23(19):2057-62.

14. Yonenobu K, Hosono N, Iwasaki M, Asano M, Ono K: Neurologic complications of surgery for cervical compression myelopathy. Spine 1991, 16(II):1277-82.

15. Hirabayashi K, Miyakawa J, Satomi K, Maruyama T, Wakano K: Operative results and postoperative progression of ossification among patients with ossification of cervical posterior longitudinal ligament. Spine 198I, 6(4):354-64.

16. Pavlov H, Torg JS, Robie B, Jahre C: Cervical Spinal Stenosis: determination with Vertebral Body Ratio Method. Radiology 1987, 164(3):77|-5. 
17. Yue WM, Tan SB, Tan MH, Koh DCS, Tan CT: The Torg-Pavlov Ratio in Cervical Spondylotic Myelopathy. Spine 200I, 26(16): 1760-4.

18. Edwards WC, LaRocca H: The Developmental Segmental Sagittal Diameter of the Cervical Spinal Canal in Patients with Cervical Spondylosis. Spine 1983, 8(I):20-7.

19. Chiba K, Toyama Y, Watanabe M, Maruiwa H, Matsumoto M, Hirabayashi K: Impact on Longitudinal Distance of the Cervical Spine on the Results of Expansive Open-door Laminoplasty. Spine 2000, 25(22):2893-8.

20. Fan D, Schwartz DM, Vaccaro AR, Hilibrand AS, Albert TJ: Intraoperative neurophysiologic detection of iatrogenic C5 nerve root injury during laminectomy for cervical compression myelopathy. Spine 2002, 27(22):2499-502.

21. Kaneko K, Hashiguchi A, Kato Y, Kojima T, Imajyo T, Taguchi T: Investigation of motor dominant C5 paralysis after laminoplasty from the results of evoked spinal cord responses. J Spinal Disord Tech 2006, 19(5):358-6I.

22. Park P, Lewandrowski KU, Ramnath S, Benzel EC: Brachial neuritis: an under-recognized cause of upper extremity paresis after cervical decompression surgery. Spine 2007, 32(22):E640-4.

23. Kubo Y, Waga S, Kojima T, Matsubara T, Kuga Y, Kakagawa Y: Microsurgical Anatomy of the Lower Cervical Spine and Cord. Neurosurgery 1994, 34(5):895-902.

Publish with Bio Med Central and every scientist can read your work free of charge

"BioMed Central will be the most significant development for disseminating the results of biomedical research in our lifetime. "

Sir Paul Nurse, Cancer Research UK

Your research papers will be:

- available free of charge to the entire biomedical community

- peer reviewed and published immediately upon acceptance

- cited in PubMed and archived on PubMed Central

- yours - you keep the copyright

Submit your manuscript here:

http://www.biomedcentral.com/info/publishing_adv.asp
BiolMedcentral 